\title{
The impact of a recultivation layer on the restoration of plant communities
}

\author{
Vladimir Ufimtsev ${ }^{1, *}$, Vladimir Androkhanov ${ }^{2}$, Svetlana Ovsyannikova ${ }^{3}$ \\ ${ }^{1}$ Federal Research Centre for Coal and Coal Chemistry SB RAS, 10 Leningradskiy avenue, \\ Kemerovo, 650065, Russia \\ ${ }^{2}$ Institute of Soil Science and Agrochemistry SB RAS, Russia \\ ${ }^{3}$ Kuzbass State Technical University named after T.F. Gorbachev, Russia
}

\begin{abstract}
Areas of coal mining dumps naturally overgrowing with vegetation in the dry-steppe (Khakassia), forest-steppe (Krasnoyarsk Krai, Kansk-Achinsk Fuel and Energy Complex, KAFEC) and subtaiga (Kemerovo region, Kuzbass) subzones were investigated. The environmental and cenotic characteristics of herbaceous communities were studied in experimental sites following the application of a fertile soil layer and in technogenic eluviums without soil improvers. The application of a fertile soil layer was found to increase both the species abundance and the projective cover of zonal species. Thus, the presence of a humus horizon promotes the formation of herbaceous ecosystems. However, this is not an unconditional factor that these ecosystems would reach the stage of zonal formations.
\end{abstract}

\section{Introduction}

The restoration of plant communities on postindustrial lands is one of the most important factors in the involvement of technogenic substrates in the biological cycle. Various recultivation techniques are currently used to increase the similarity of technogenic ecosystems to natural ecosystems [2]. The rate of ecosystem restoration largely depends on the restoration of soil and environmental functions, which, in turn, depends on the natural and climatic conditions of the territory where the technogenic objects are located. In this work, we analyse restoration processes in the plant communities of embryozems and technozems formed on rock dumps produced by coal mines in various climatic and edaphic conditions.

\section{Materials and Methods}

Experimental plots were laid on old (25-35 years old) naturally overgrowing dumps formed as a result of coal mining, located in three regions of Siberia, different in natural and

\footnotetext{
*Corresponding author: uwy2079@gmail.com
} 
climatic conditions and plant environment: the steppe zone - the Republic of Khakassia (Chernogorskiy coal mine), the forest-steppe zone - the forest-steppe of Krasnoyarsk Krai (Nazarovsky coal mine), and the subtaiga zone of the foothills of Gornaya Shoria, Kemerovo region (Listvyansky coal mine). In each region, sites for the application of soil improvers (fertile soil layer - FSL, or potentially fertile layer - PFS - loess-like loams) [4] were selected; control sites were fallow lands of a similar age. Each experimental option contained a series of five model test plots of the size conventionally used to study herbaceous communities, i.e. $10 \times 10 \mathrm{~m}$ [5]. The differentiation of species into environmental-cenotic groups was carried out according to [7]. The IBIS software by A.A. Zverev [8] was used to analyse geobotanical descriptions.

\section{Results and discussion}

On the experimental plots, 146 species of higher vascular plants belonging to 32 families were found. A direct dependence of the number of species on the mesophytization of growing conditions was observed, both on dumps and fallow lands: $20-31$ species were recorded in the steppe, $34-40$ in the forest-steppe, and $38-52$ in the subtaiga. In the steppe zone, the species abundance directly depended on the edaphic factor: without FSL, this indicator was $35.5 \%$ lower than in the control group; however, with FSL application, it was $28.3 \%$ lower. In the forest-steppe, such a dependence was not observed. In the subtaiga on dumps with FSL application, the number of species was higher than that in the control group by $18 \%$ (Table 1$)$.

Table 1. Environmental-cenotic structure of herbaceous communities

\begin{tabular}{|c|c|c|c|c|c|c|c|}
\hline \multirow{2}{*}{\multicolumn{2}{|c|}{ Experimental plots }} & \multicolumn{5}{|c|}{ Number of species, pcs } & \multirow{3}{*}{$\frac{\text { Total }}{20}$} \\
\hline & & \multirow{2}{*}{$\begin{array}{c}\text { Forest } \\
0\end{array}$} & \multirow{2}{*}{$\begin{array}{c}\text { Meadow } \\
2\end{array}$} & \multirow{2}{*}{$\begin{array}{c}\begin{array}{c}\text { Meadow- } \\
\text { steppe }\end{array} \\
5\end{array}$} & \multirow{2}{*}{$\begin{array}{c}\text { Steppe } \\
0\end{array}$} & \multirow{2}{*}{$\begin{array}{c}\text { Ruderal } \\
13\end{array}$} & \\
\hline \multirow{3}{*}{$\begin{array}{l}\text { Steppe } \\
\text { (Khakassia) }\end{array}$} & $\begin{array}{l}\text { Without } \\
\text { FSL }\end{array}$ & & & & & & \\
\hline & $\begin{array}{l}\text { With } \\
\text { FSL }\end{array}$ & 0 & 3 & 2 & 7 & 9 & 21 \\
\hline & Control & 0 & 6 & 4 & 14 & 7 & 31 \\
\hline \multirow{3}{*}{$\begin{array}{l}\text { Forest- } \\
\text { steppe } \\
\text { (KAFEC) }\end{array}$} & $\begin{array}{l}\text { Without } \\
\text { PFS }\end{array}$ & 1 & 19 & 8 & 4 & 8 & 40 \\
\hline & $\begin{array}{l}\text { With } \\
\text { PFS }\end{array}$ & 2 & 16 & 6 & 1 & 9 & 34 \\
\hline & Control & 6 & 19 & 3 & 2 & 10 & 40 \\
\hline \multirow{3}{*}{$\begin{array}{l}\text { Subtaiga } \\
\text { (Kuzbass) }\end{array}$} & $\begin{array}{l}\text { Without } \\
\text { FSL }\end{array}$ & 4 & 17 & 2 & 3 & 12 & 38 \\
\hline & $\begin{array}{l}\text { With } \\
\text { FSL }\end{array}$ & 3 & 28 & 5 & 1 & 15 & 52 \\
\hline & Control & 2 & 24 & 5 & 0 & 14 & 45 \\
\hline
\end{tabular}

Species belonging to five environmental-cenotic groups were presented: forest, meadow, meadow-steppe, steppe and ruderal.

In the steppe zone, dumps were predominantly occupied by ruderal species. Their participation in the areas with and without FSL application was $42.8 \%$ and $65 \%$, respectively. This indicator is significantly higher than that in the control group $(22.5 \%)$, where the zonal type of plant succession was observed. The fraction of steppe species 
developed on FSL was 33\%, which is the second largest after ruderals. Steppe species were not observed. The fraction of meadow plants on dumps was minimal (10-14\%), which is associated with a sharp moisture deficit in the substrate of both embryozems and technozems. The control site was dominated by steppe (45\%) and complementary meadowsteppe species $(12.9 \%)$, which indicates zonal vegetation on fallows. The share of ruderal species $(22.5 \%)$ and a significant share of meadow species $(19.3 \%)$ is a sign of a more favourable water regime of old arable soils compared to dump habitats. In the steppe zone, no forest species were observed in any of the experimental plots.

Meadow species prevailed in the forest-steppe subzone. They were represented in equal fractions both on dumps and in the control site $(47-47.5 \%)$. On dumps, the share of meadow-steppe and steppe species was slightly higher $(20.5-30 \%$ in total), with this indicator in the control site being $12.5 \%$. The share of forest species was higher in the control site (15\%), while on dumps it was only $2.5-5.8 \%$, which indicates the preservation of an unstable water regime in old dumps. Ruderal species occupy the second position after meadow species $(20-26.5 \%)$. Meadow-steppe species act as community assectators, accounting for $7.5-20 \%$; steppe species occur sporadically $(2.9-10 \%)$.

In the subtaiga zone, a group of meadow species, both on dumps and in the control site, formed half of the species composition $(44-53 \%)$. The participation of ruderal species was significant $(28.8-31.5 \%)$ both on dumps and in the control site. Meadow-steppe species were ubiquitous $(5.2-11.1 \%)$. Forest species were represented in the amount of $4.4-$ $10.5 \%$, indicating the taiga plant environment. Steppe species occurred randomly or were absent.

The projective cover of the environmental-cenotic groups of plants and their representative species is the most significant indicator for the direction of plant succession and the characteristics of growing conditions (Table 2).

Table 2. Average projective cover (\%) of environmental-cenotic groups of plants in communities

\begin{tabular}{|c|c|c|c|c|c|c|c|}
\hline \multirow{2}{*}{\multicolumn{2}{|c|}{ Experimental plots }} & \multicolumn{5}{|c|}{ Projective cover, $\%$} & \multirow[b]{2}{*}{ Total } \\
\hline & & Forest & Meadow & $\begin{array}{l}\text { Meadow- } \\
\text { steppe }\end{array}$ & Steppe & Ruderal & \\
\hline \multirow{3}{*}{$\begin{array}{l}\text { Steppe } \\
\text { (Khakassia) }\end{array}$} & $\begin{array}{l}\text { Without } \\
\text { FSL }\end{array}$ & 0.0 & 2.1 & 42.1 & 0.0 & 30.7 & 74.8 \\
\hline & $\begin{array}{l}\text { With } \\
\text { FSL }\end{array}$ & 0.0 & 0.4 & 30.0 & 18.7 & 50.8 & 99.9 \\
\hline & Control & 0.0 & 9.2 & 5.1 & 43.7 & 7.5 & 65.6 \\
\hline \multirow{3}{*}{$\begin{array}{l}\text { Forest- } \\
\text { steppe } \\
\text { (KAFEC) }\end{array}$} & $\begin{array}{l}\text { Without } \\
\text { PFS }\end{array}$ & 0.8 & 56.4 & 33.7 & 0.1 & 25.3 & 100 \\
\hline & $\begin{array}{l}\text { With } \\
\text { PFS }\end{array}$ & 0.1 & 75.0 & 27.9 & 0.4 & 1.2 & 100 \\
\hline & Control & 21.5 & 51.9 & 6.0 & 1.6 & 19.0 & 90.9 \\
\hline \multirow{3}{*}{$\begin{array}{l}\text { Subtaiga } \\
\text { (Kuzbass) }\end{array}$} & $\begin{array}{l}\text { Without } \\
\text { FSL }\end{array}$ & 0.1 & 72.0 & 15.7 & 0.0 & 3.6 & 91.4 \\
\hline & $\begin{array}{l}\text { With } \\
\text { FSL }\end{array}$ & 0.5 & 33.4 & 52.3 & 1.1 & 6.2 & 92.6 \\
\hline & Control & 7.1 & 85.5 & 0.1 & 1.3 & 7.6 & 100 \\
\hline
\end{tabular}

In the steppe zone on dumps without FSL application, the basis of the projective cover was Calamagrostis epigeios L. (up to $70 \%$ in different plots). Although belonging to the 
meadow-steppe species, this plant is a representative of early and medium succession species of simple plant groups. Therefore, the presence of this plant cannot be considered as a sign of zonal vegetation. Among the ruderal species, the most active were Elytrigia repens (L.) Devs. Ex Nevski (up to 80\%), Artemisia vulgaris L. (up to 40\%), Cirsium setosum (Willd.) Bes (up to 30\%), Convolvulus bicuspidatus Fisch. ex Link (up to 20\%) and Carduus nutans L. (up to 5\%), which grow fragmentarily, in clumps of up to several tens of square meters. No other types participated in forming the projective cover.

In the sites with FSL application, ruderals retained the leading position. However, steppe species in strictly local clumps also appeared, including Allium senescens L. (up to 20\%), Artemisia annua L. (up to 30\%) and Vincetoxicum thesioides Freyn (up to 10\%). Most likely, these species had been brought to the dump with an FSL substrate. Meadow species were represented by single specimens.

In the control site, while maintaining a high proportion of weeds (A. vulgaris up to $40 \%$, Linaria vulgaris L. up to $10 \%$ ), the basis of the projective cover was formed by the steppe species Poa stepposa (Krylov) Roshev (up to 20\%), Helictotrichon desertorum (Less.) Nevski (up to 20\%), Potentilla longifolia Willd. ex Schltdl. (up to 20\%), Stipa capillata L. (up to $5 \%$ ), etc., as well as by meadow-steppe species Galium verum L. (up to 5\%), Medicago falcata (5\%), etc.

In the forest-steppe zone, in the site without FSL application, the projective cover was formed by meadow species with a high activity of ruderals. Among the former were Poa pratensis L. (up to 40\%), Equisetum arvense L. (up to 15\%), Achillea millefolium L. (up to $5 \%$ ) and Medicago lupulina L. (up to 5\%). Among ruderals, Vicia amoena Fisch. (up to $5 \%$ ) and Vicia cracca L. (up to 5\%) dominated, with a high proportion of Melilotus officinalis (up to $30 \%$ ) and Tussilago farfara L. (up to $10 \%$ ), which is characteristic of early succession stages.

The dumps with FSL application were dominated by meadow species, with the absolute dominant being Poa pratensis L. (up to 70\%). The co-dominants were Equisetum arvense L. (up to 20\%), Geranium pratense L. (up to 5\%), Thalictrum simplex L. (up to 5\%) and Vicia cracca L. (up to 5\%), meadow-steppe Galium verum L. (up to 10\%), Pimpinella saxifraga L. (up to $5 \%$ ), etc. Other types of zonal vegetation were evenly-distributed community assectators with shares not exceeding 1-2\%. Ruderal species were represented by single specimens $(1.2 \%)$, which indicates the transition of the community to the stage of a closed (zonal) phytocenosis.

In the control site, the basis of the projective cover was formed by meadow species characteristic of dumps: a high proportion of Bromopsis inermis L. (up to 30\%), which was probably preserved as a sign of former culture phytocenoses. The contribution of forest species was significant, primarily Brachypodium pinnatum (L.) Beauv. (up to 20\%) and Heracleum dissectum L. (up to 10\%), due to the significant mesophytization of the former arable lands as compared to dump habitats. Among the meadow-steppe species, the projective cover was formed by G. Verum (up to 5\%); the Rhinanthus autumnalis L. semiparasite was widespread among the ruderal species (up to 50\%). Among the steppe species, Vicia unijuga A. Br. (up to 5\%) was a prominent assectator.

In the subtaiga zone, on dumps without FSL application, meadow herbaceous communities were formed. The share of meadow herbaceous communities in the projective cover was five times higher than that in all other groups combined. The edificator was the high late successional cereal Dactylis glomerata L. (up to 60\%), a typical representative of complex plant groups in dumps. The co-dominant was Festuca pratensis L. (up to 15\%). The assectators were mainly cereals: Phleum pratense L. (up to 10\%), Agrostis gigantea L. (up to 3\%), Poa angustifolia L. (up to 1\%); legumes - Amoria repens (L.) C. Presl. (up to $2 \%$ ) and Vicia cracca L. (up to 2\%); herbs - Potentilla canescens Bess (up to 3\%), Achillea millefolium L. (up to 2\%); and other meadow species less than $1 \%$ each. Among the 
meadow-steppe species, Pimpinella saxifraga L. (up to 20\%) and Centaurea scabiosa L. (up to $10 \%$ ) were observed. The ruderal component was represented by Convolvulus arvensis L., Taraxacum officinale L. and Stellaria graminea L. (1\% each), the rest were singular. Forest species had no participation in the composition of the projective cover.

In the areas with FSL application, the leading role in the projective cover belonged to meadow-steppe species: Centaurea scabiosa L. (up to 30\%), Pimpinella saxifraga L. (up to $30 \%$ ) and Fragaria viridis L. (up to 30\%). However, it should be noted that these species are typical representatives of medium and late successional complex plant groups of Kuzbass dumps and are the markers of a xeromorphic ecocline (the dump habitat under the conditions of sufficient general moisture). Therefore, such a high projective cover is not typical of zonal meadow-steppe phytocenoses. Meadow species in the projective cover were the second largest, with the most abundant being Festuca pratensis L. (up to 40\%), Galium mollugo L. (up to 10\%), A. millefolium (up to 5\%), Potentilla canescens Bess (up to $5 \%$ ), D. glomerata (up to $2 \%$ ), Leucanthemum vulgare L. (up to $2 \%$ ), Phleum pratense L., Trifolium pratense L., V. amoena and $V$. cracca ( $2 \%$ each). Ruderals were of secondary importance, with the most abundant being Malva neglecta Wallr. (up to 2\%) and Taraxacum officinale F.H. Wigg (up to 2\%). The steppe species Senecio jacobaea L. was also recorded (up to 2\%). Lathyrus pisiformis L. was ubiquitous (1\%) among the forest species, other plants were found as single specimens.

In the control site, the proportion of the projective cover of meadow species was the highest among all the studied experimental plots. The edificators in the community were $D$. glomerata (up to 60\%), V. amoena (up to 40\%), $H$. perforatum (up to $20 \%$ ) and $P h$. pratense (up to 15\%) in the upper substage, P. angustifolia (up to 15\%) in the lower substage. The assectators were A. millefolium (up to 5\%), F. pratensis (up to $15 \%$ ) and $T$. pratense L. (up to 3\%). Bromopsis inermis L. was found in clumps (up to 3\%). The semiparasite Rhinanthus vernalis L. was sporadically found (up to 5\%), which is a sign of the initial stage of meadow phytocenosis formation. Compared to the dump habitats, the presence of the forest component, in particular, Fragaria vesca L. (up to 5\%) and Chamerion angustifolium L. (up to 3\%), was more prominent. Among the ruderals, Taraxacum officinale L. (up to $3 \%$ ) and Pastinaca sylvestris L. (up to 1\%) demonstrated the highest activity, while the rest of the species had no phytocenotic significance.

\section{Conclusion}

The application of a zonal humus fertile soil layer as a soil conditioner improves the quantitative and qualitative characteristics of the herbaceous cover. Natural overgrowing of overburden dump habitats in each natural and climatic subzone leads to the formation of herbaceous communities with an internal structure shifted by one step towards xeromorphization in comparison with the vegetation environment of undisturbed territories. In the subtaiga subzone, the species abundance on dumps after FSL application is even higher than on that on the former arable lands. However, in the steppe subzone, zonal phytocenoses are not restored even after FSL application.

The study was supported by the Russian Foundation for Basic Research, grant No. 19-29-05086.

\section{References}

1. A.N. Kupriyanov, V.I. Ufimtsev, Yu.A. Manakov, et al., Methodological recommendations for the restoration of meadow-steppe vegetation on dumps of the coal industry in Kuzbass (Irbis: Kemerovo, 2017)

2. I.M. Gadzhiev, V.M. Kurachev, V.A. Androkhanov, Strategy and prospects for solving the problems of recultivation of disturbed lands ( CERIS: Novosibirsk, 2001) 
3. E.M. Lavrenko, A.A. Korchagin, Field Geobotany (Moscow, Lenigrad, 1976)

4. T.A. Rabotnov, Phytocenology ( Moscow University Press: Moscow, 1992)

5. A.A. Zverev, Information technologies in the study of vegetation (Tomsk, 2007)

6. A.N. Kupriyanov, Yu.A. Manakov, L.P. Barannik, Restoration of ecosystems on the dumps of the mining industry of Kuzbass (Acad. Publishing House "Geo": Novosibirsk, 2010)

7. N.N. Lashchinsky, S.A. Sheremetova, N.I. Makunina, et al., The flora of the Karakan ridge (Acad. Publishing House "Geo": Novosibirsk, 2011)

8. A.A. Zverev, Informational technologies in the study of vegetation cover (Tomsk, 2007) 